This article was downloaded by:[Australian National University Library]

On: 27 May 2008

Access Details: [subscription number 773444559]

Publisher: Informa Healthcare

Informa Ltd Registered in England and Wales Registered Number: 1072954

Registered office: Mortimer House, 37-41 Mortimer Street, London W1T 3JH, UK

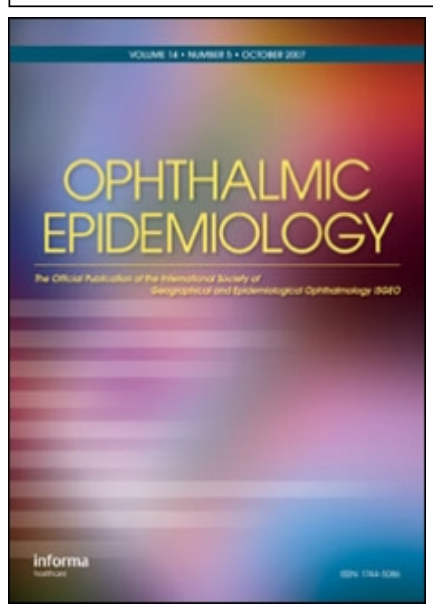

\title{
Ophthalmic Epidemiology
}

Publication details, including instructions for authors and subscription information: http://www.informaworld.com/smpp/title content=t713734444 Can Information on the Purpose of Spectacle Use and Age at First Use Predict Refractive Error Type?

Jenny Ip ${ }^{\text {a; Dana Robaei }}{ }^{\mathrm{a}}$; Elena Rochtchina ${ }^{\mathrm{a}}$; Kathryn Rose ${ }^{\mathrm{b}}$; Wayne Smith ${ }^{\mathrm{c}}$; Jie Jin Wang a ${ }^{\text {; }}$ Paul Mitchell ${ }^{\text {a }}$

a Department of Ophthalmology (Centre for Vision Research, Westmead Hospital) and the Westmead Millennium Institute, University of Sydney, Westmead, Australia

${ }^{b}$ School of Applied Vision Sciences, Faculty of Health Sciences, University of

Sydney, Sydney, Australia

${ }^{\mathrm{c}}$ National Centre for Epidemiology and Population Health, Australian National

University, Canberra, Australia

Online Publication Date: 01 March 2007

To cite this Article: Ip, Jenny, Robaei, Dana, Rochtchina, Elena, Rose, Kathryn, Smith, Wayne, Wang, Jie Jin and Mitchell, Paul (2007) 'Can Information on the Purpose of Spectacle Use and Age at First Use Predict Refractive Error Type?', Ophthalmic Epidemiology, 14:2, 88 - 92

To link to this article: DOI: $10.1080 / 09286580600943481$

URL: http://dx.doi.org/10.1080/09286580600943481

\section{PLEASE SCROLL DOWN FOR ARTICLE}

Full terms and conditions of use: http://www.informaworld.com/terms-and-conditions-of-access.pdf

This article maybe used for research, teaching and private study purposes. Any substantial or systematic reproduction, re-distribution, re-selling, loan or sub-licensing, systematic supply or distribution in any form to anyone is expressly forbidden.

The publisher does not give any warranty express or implied or make any representation that the contents will be complete or accurate or up to date. The accuracy of any instructions, formulae and drug doses should be independently verified with primary sources. The publisher shall not be liable for any loss, actions, claims, proceedings, demand or costs or damages whatsoever or howsoever caused arising directly or indirectly in connection with or arising out of the use of this material. 


\title{
Can Information on the Purpose of Spectacle Use and Age at First Use Predict Refractive Error Type?
}

\author{
Jenny Ip, ${ }^{1}$ Dana Robaei, ${ }^{1}$ Elena Rochtchina, ${ }^{1}$ Kathryn Rose, ${ }^{2}$ Wayne Smith, ${ }^{3}$ Jie Jin Wang, ${ }^{1}$ and Paul Mitchell ${ }^{1}$ \\ ${ }^{1}$ University of Sydney, Department of Ophthalmology (Centre for Vision Research, Westmead Hospital) \\ and the Westmead Millennium Institute, Westmead, Australia \\ ${ }^{2}$ University of Sydney, School of Applied Vision Sciences, Faculty of Health Sciences, Sydney, Australia \\ ${ }^{3}$ National Centre for Epidemiology and Population Health, Australian National University, Canberra, Australia
}

\begin{abstract}
Purpose: To assess the sensitivity and specificity of predicting refractive error type using information from a four-item questionnaire on the purpose of spectacle use and age at first use. Methods: The Sydney Myopia Study examined 1,740 year 1 (78.9\% response) and 2,353 year 7 students $(75.3 \%$ response) from a random cluster sample of 34 primary and 21 secondary schools across Sydney. Parents of participants completed a four-item questionnaire that sought data on parental spectacle use, age at first use, and purpose of use (for clear distant vision, close work, or both). Prescriptions were obtained for 720 of $3,209(22 \%)$ parents $(73 \%$ of those approached) for validation. A receiver operating characteristic (ROC) curve was used to determine the optimal cutoff age for spectacle use in myopia classification. Results: Using the ROC curve, a cutoff age of 30 years at first spectacle use produced the highest accuracy in determining myopia. We combined information on the purpose for using spectacles (for distant and near vision) and age of first use at $\mathbf{3 0}$ years or younger to determine myopia, otherwise hyperopia. Validated against prescriptions, the sensitivity and specificity of these predictions were 0.89 and $\mathbf{0 . 8 3}$, respectively, for myopia. The specificity was 0.92 for hyperopia and $\mathbf{0 . 8 0}$ for astigmatism, though corresponding sensitivities were lower at 0.23 and 0.46 , respectively. Conclusions: In a sample of the parents of Sydney Myopia Study participants, information on the purpose of spectacle use with an age-at-first-use criterion can identify myopic refractive error with reasonable sensitivity and specificity. This four-item questionnaire may assist future epidemiological studies of screening for myopia.
\end{abstract}

\section{INTRODUCTION}

The impact of parental myopia on childhood refraction may be mediated by shared genes, shared environmental effects such as modulation of a child's environment by myopic parents, or a combination of the two. ${ }^{1}$ In epidemiological studies, children of myopic parents have been shown to have a higher risk of

Received 29 March 2006; accepted 4 August 2006. Keywords: Myopia, Refractive Error, Refraction, Spectacles, Sydney Childhood Eye Study, Sydney Myopia Study. Correspondence to:

Jie Jin Wang

University of Sydney

Department of Ophthalmology

Centre for Vision Research

Westmead Hospital

Hawkesbury Road, Westmead, NSW, Australia, 2145

email: jiejin_wang@wmi.usyd.edu.au myopia, ${ }^{2,3}$ as well as longer eyes ${ }^{4-6}$ and a higher severity and greater progression of myopia.

In population-based study of refractive errors, parental myopia has been determined by various methods, including direct eye examination of parents such as in the Beaver Dam Eye Study and the Framingham Offspring Eye Study, ${ }^{7,8}$ and by questionnaires. ${ }^{3,4,9}$ The potential advantage of using questionnaires in a general population with a relatively low prevalence of myopia to determine refractive error type is cost-effective, ${ }^{10}$ though it is likely to be offset by some degree of misclassification. There are no good validation data on the sensitivity and specificity of using questionnaire information against spectacle prescriptions as the gold standard.

A questionnaire to determine refractive error based on spectacle use was devised by Zadnik et al. ${ }^{4}$ and used in the Orinda Longitudinal Study of Myopia (OLSM). The questionnaire asked respondents about the age at first spectacle use and the purpose of spectacle use, such as for far distance viewing, for near work, or for both far distance and near work. This questionnaire was validated for accuracy in refractive type classification by 
Walline et al. ${ }^{11}$ in a clinical setting that included participants across a broad age range (18-80 years).

The Sydney Myopia Study adopted the Zadnik questionnaire ${ }^{4}$ for use in a population-derived school-based survey of children. We used information collected by these questions to determine refractive error type in parents of schoolchildren of two age cohorts (aged predominantly between 6 and 12 years). In the current study, we aimed to validate the predictive value of the four-item questionnaire in identifying refractive error type in a sample of Australian adults, the parents of children in our survey.

\section{METHODS}

\section{Study population}

Participants were parents of children enrolled in the Sydney Myopia Study, a population-based survey of the eye health of children resident in the metropolitan area of Sydney, Australia. Because parents of the participants in the Sydney Myopia Study were derived from random samples of urban and suburban communities in Sydney, findings from this study may be applicable to middle-aged Australian adults in urban and suburban areas. Approval for the study was obtained from the Human Research Ethics Committee of the University of Sydney, the New South Wales Department of Education, and the Catholic Education Office. The study adhered to the tenets of the Declaration of Helsinki.

Methods used to identify and select the childhood sample have been reported. ${ }^{12}$ In brief, all schools within the city of Sydney were stratified by socioeconomic status (SES), and a proportionate mix of government and private-funded schools (34 primary schools and 21 high schools) were identified through a random cluster-sampling method. All year 1 and year 7 children were invited to attend, and response rates were $78.9 \%$ and $75.3 \%$, respectively.

\section{Questionnaire data}

Before the child's eye examination, parents completed a detailed questionnaire, which included four items about parental use/wearing of spectacles. The first question was (1) "Do you wear glasses or contact lenses?" and had three possible responses of "yes," "no," or "don't know." Other questions were (2) "At what age did you start wearing glasses?" (3) "What do you wear glasses or contact lens primarily for?" (possible answers were "to see clearly in the distance." "for reading, working at a computer, or other close work," or "equally important for distance and close work") and (4) "Do you have astigmatism?" (answers were "yes," "no," and "don't know"). It must be acknowledged that spectacles used for far distance vision may indicate either myopia or moderate hyperopia, which cannot be overcome by accommodation, with or without astigmatism.

All parents who reported using spectacles were contacted and asked to provide a copy of their current glasses prescription. Permission was sought from parents to contact optometrists or optical dispensers if the prescriptions were unable to be found. This process was repeated on several occasions, either by mailouts, e-mail, or by direct telephone contact to maximise the number of parental prescriptions obtained. The spectacle use questions were then validated against the prescriptions for their ability to correctly identify the presence and type of refractive error.

\section{Definitions}

The spectacle use questions defined parental myopic refractive error if spectacles were used for distance viewing, or for both distance viewing and close work. Furthermore, spectacle use was required to commence at or before age 30 years (determined by a receiver operating characteristic [ROC] curve) if used for both distance viewing and close work. Astigmatism was defined if so indicated by the parent.

Parental prescriptions of spherical equivalent $(\mathrm{SE}) \leq-0.5$ diopters (D) were defined as myopic, $\mathrm{SE} \geq+2.0 \mathrm{D}$ or addition lenses $\geq+3.0 \mathrm{D}$ as moderately hyperopic, and cylinder $\geq 1.0 \mathrm{D}$ as astigmatic. Low prescriptions were defined for SE between $-0.4 \mathrm{D}$ to $+0.5 \mathrm{D}$, and low plus prescriptions where $\mathrm{SE}$ was greater than $0.5 \mathrm{D}$ but less than $2.0 \mathrm{D}$.

\section{Data analysis}

This is a cross-sectional analytical study pertaining to a diagnostic test instrument (questionnaire). Data were analysed by using Statistical Analysis System software (SAS Institute, Cary, $\mathrm{NC}$ ). Validity of the four-item survey was assessed for sensitivity and specificity for myopia, hyperopia, and astigmatism separately. For myopia, the sensitivity was measured in the group of parents with myopic prescriptions, compared to the proportion identified as myopic using the questionnaire. Similarly, specificity was measured in the group of parents with nonmyopic prescriptions, identified as not myopic using the questionnaire. Similar definitions of sensitivity and specificity were used for hyperopia and astigmatism.

A ROC curve was generated for the age at first spectacle use by computing the true-positive rate (sensitivity) and false-positive rate (1-specificity) of the survey at several cutpoints. The age cutpoint producing highest accuracy was represented by the point furthest away from the diagonal of the ROC curve.

\section{RESULTS}

\section{Population characteristics}

Of the 8,188 parents with children participating in the Sydney Myopia Study, 3,209 (39\%) reported spectacle use. Of the parents $(n=983)$ who were recontacted, a total of 720 parents $(73.2 \%)$ provided the information requested and were included in the validation analysis; $56.1 \%$ were female, with mean age of 43.4 years (standard deviation [SD] 6.5 years: range 27-68 years). Demographic characteristics of parents reporting spectacle use, with and without available prescriptions, show that parents who provided prescriptions were more likely to be female, of European Caucasian ethnicity, and more likely to have a university degree (Table 1). 


\begin{tabular}{|c|c|c|c|}
\hline $\begin{array}{l}\text { Demographic } \\
\text { variable }\end{array}$ & $\begin{array}{c}\text { Prescription } \\
\text { data } \\
\text { available }\end{array}$ & $\begin{array}{c}\text { Prescription } \\
\text { data not } \\
\text { available }\end{array}$ & P-value \\
\hline Mean age (yr) & 43.4 & 44.1 & 0.02 \\
\hline Female (\%) & 56.1 & 49.7 & 0.002 \\
\hline Ethnic background (\%) & & & 0.0001 \\
\hline Caucasian & 78.2 & 66.6 & \\
\hline East Asian & 12.4 & 20.3 & \\
\hline Other ethnic background & 9.4 & 13.2 & \\
\hline Highest education level (\%) & & & 0.009 \\
\hline Did not complete high school & 19.0 & 22.8 & \\
\hline Completed high school or college & 33.9 & 36.4 & \\
\hline Completed university & 47.1 & 40.9 & \\
\hline
\end{tabular}

Of the parents included in this study, most $(n=443 ; 65 \%)$ indicated spectacle use to see clearly in the distance or for both distance and close work. The mean age $( \pm \mathrm{SD})$ at first spectacle use was $26.5 \pm 13.4$ years (range 1-60 years). The distribution of right and left eye prescriptions is shown in Figure 1.

\section{The age at first spectacle use}

A ROC curve depicting the sensitivity and specificity of questionnaire information for various cut-points of the age at first spectacle use was plotted by using cutpoints at ages 5, 10, 12, $14,15,16,17,18,19,20,25,27,30,35,40$, and 50 years (Figure 2). Spectacle use before or at age 30 years produced the best sensitivity $(0.88,95 \%$ confidence interval [CI]: $0.85-0.92)$ and specificity (0.83, CI: $0.78-0.87)$ for myopia (kappa coefficient $=0.71)$

\section{Identifying myopia}

In this sample, there were 416 (58\%) myopic and 304 (42\%) nonmyopic prescriptions; 77 parents had incomplete questionnaire data, leaving 643 prescriptions-373 myopic (58\%) and 270 nonmyopic (42\%) —available for the myopia analysis.

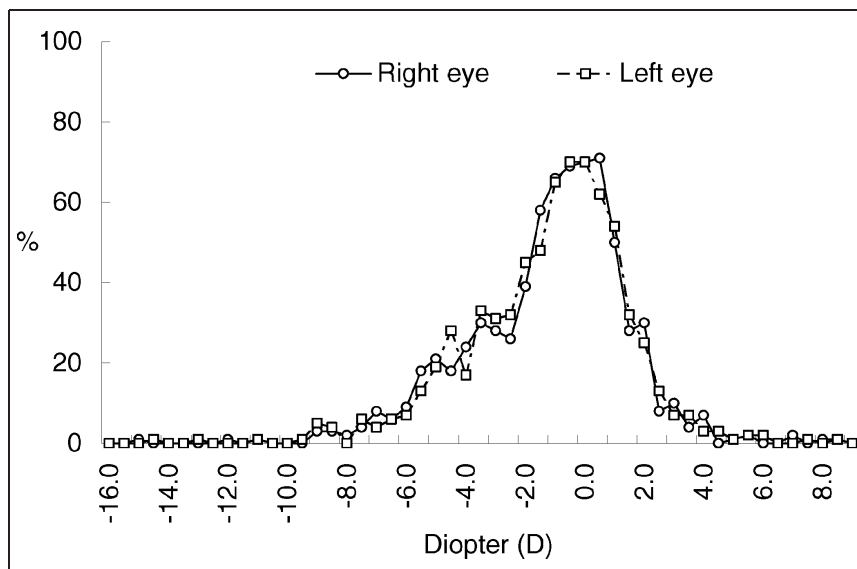

Figure 1. Distribution of prescriptions in spherical equivalent for right and left eyes among parents $(n=720)$. Values on $X$-axis indicate minimum of intervals.
Table 2. Classification of refractive error among parents by the spectacle use questionnaire, validated against spectacle prescriptions

\begin{tabular}{|c|c|c|c|}
\hline $\begin{array}{l}\text { Refractive error type } \\
\text { defined from prescription }\end{array}$ & $\mathrm{n}$ & $\begin{array}{c}\text { Correctly } \\
\text { classified \% (n) }\end{array}$ & $\begin{array}{c}\text { Incorrectly } \\
\text { classified \% (n) }\end{array}$ \\
\hline \multicolumn{4}{|l|}{ Myopia* } \\
\hline Present & 373 & 88.5 (330) & $11.5(43)$ \\
\hline Absent & 270 & $82.6(223)$ & $17.4(47)$ \\
\hline \multicolumn{4}{|l|}{ Hyperopia ${ }^{\dagger}$} \\
\hline Present & 102 & $22.6(23)$ & 77.5 (79) \\
\hline Absent & 522 & $91.6(478)$ & $8.4(44)$ \\
\hline \multicolumn{4}{|l|}{ Astigmatism $\ddagger$} \\
\hline Present & 136 & $46.3(63)$ & $53.7(73)$ \\
\hline Absent & 364 & 80.2 (292) & $19.8(72)$ \\
\hline \multicolumn{4}{|c|}{$\begin{array}{l}* \text { Spherical equivalent } \leq-0.5 \mathrm{D} \text {. } \\
\dagger \text { Spherical equivalent } \geq+2.0 \mathrm{D} \text {. } \\
\ddagger \text { Cylinder } \geq 1.0 \mathrm{D} .\end{array}$} \\
\hline
\end{tabular}

The majority ( $\mathrm{n}=330 ; 88.5 \%)$ of parents with myopic prescriptions were correctly identified (true positive) by the questions asking about both the purpose of spectacle use and age at first use (Table 2). Parents with myopic prescriptions who were not classified as myopic (false negative) by the questionnaire reported spectacle use for reading only $(n=31)$ or spectacle use after age 30 years $(\mathrm{n}=12)$.

Most parents $(n=223 ; 82.6 \%)$ with nonmyopic prescriptions were correctly identified as non-myopic (true negative). Among parents falsely identified as myopic (false positive), prescriptions tended to be either low $(n=20)$, low plus $(n=13)$ or moderately hyperopic $(n=14)$ prescriptions. In this study, the questionnaire had sensitivity of 0.83 (CI: $0.78-0.87$ ) and specificity of 0.89 (CI: $0.85-0.92$ ) for predicting parental myopia.

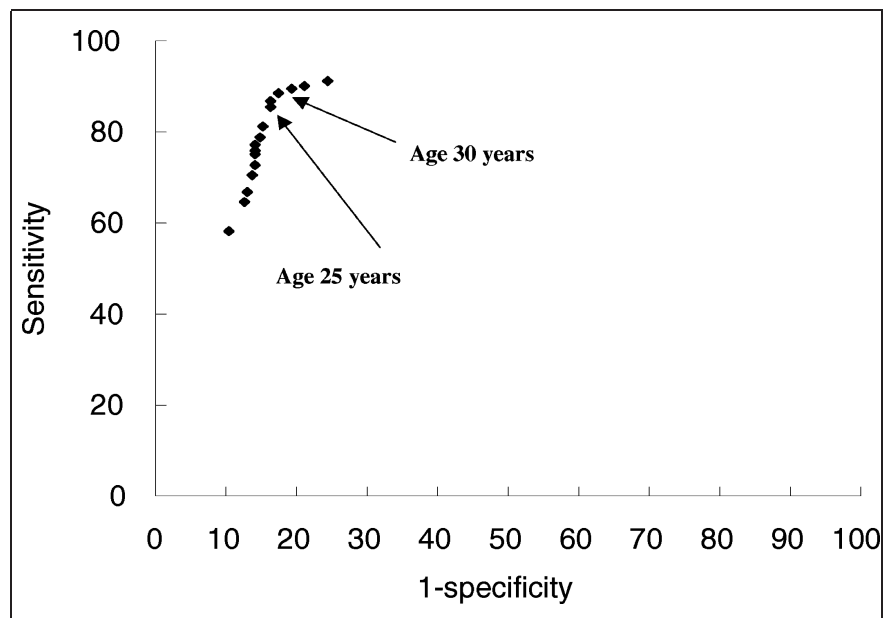

Figure 2. Receiver operating characteristic (ROC) curve for sensitivity and specificity for age at first spectacle use in identifying myopia among a sample of Australian adults $(n=643)$. Data points represent (from left to right) ages $5,10,12,14,15,16,17,18,19$, $20,25,27,30,35,40$, and 50 years. 


\section{Identifying hyperopia and astigmatism}

A substantially smaller proportion of parents $(n=23 ; 22.6 \%)$ with hyperopic prescriptions were correctly identified by using the questionnaire (true positive), whereas the vast majority $(\mathrm{n}=478 ; 91.6 \%)$ of parents with nonhyperopic prescriptions were correctly identified (true negative, Table 2). For predicting moderate hyperopia, the questionnaire had quite a low sensitivity $(0.23$, CI: $0.15-0.32)$ but a relatively high specificity $(0.92$, CI: 0.89-0.94).

Of all parents with available prescriptions, 220 (30.6\%) did not answer the astigmatism question. While most parents ( $\mathrm{n}=$ $292 ; 80.2 \%$ ) correctly reported the absence of astigmatic prescriptions (true negative), fewer parents were able to confirm its presence $(n=63 ; 46.3 \%)$. Many parents $(n=72 ; 19.8 \%)$ who indicated they were astigmatic in the questionnaire did not have astigmatism (false positive). For predicting astigmatism, the questionnaire had a sensitivity of 0.46 (CI: 0.38-0.55) and specificity of 0.80 (CI: 0.76-0.84).

\section{DISCUSSION}

In this study, we assessed the accuracy of the four-item questionnaire on spectacle use developed by Zadnik et al. ${ }^{4}$ to determine refractive error type among a sample of Australian adults, who were parents of children examined in the Sydney Myopia Study. Compared against spectacle prescriptions, the questionnaire was found to be reasonably accurate for identifying myopia but was substantially less accurate for identifying either hyperopia or astigmatism.

The sensitivity and specificity values for our questionnaire to detect myopia were quite similar to a validation of the same questions reported by Walline et al. ${ }^{11}$ ( 0.76 and 0.74 , respectively) for optometry clinic outpatients. The slightly higher sensitivity in the current study (0.89) could have resulted from an older age cutpoint for the age at first use of spectacles, leading to the inclusion of participants with later-onset myopia (Walline et al. used a cutpoint of 16 years). The sensitivity to detect astigmatism was lower in our study (0.46) than reported by Walline et al. (0.66), though the specificity was similar. While the same astigmatism question (“do you have astigmatism?") was used in both studies, accuracy levels may have been influenced by differences in the demographics of respondents. Clinic patients may have had a greater awareness and knowledge of refractive errors than parents in a community setting.

Previous validation studies have reported similar levels of accuracy for questionnaires about the purpose of spectacle use, though differences in study settings and participant characteristics have impeded the generalisation of their findings. ${ }^{3,10,13}$ In a small study by Irribarren et al., ${ }^{13}$ myopia was defined in participants based on "the need of lenses for far distance at a young age." Refractive error was correctly determined for all participants (54 myopic and 5 hyperopic adults). However, this small sample was selected from an optometry outpatient clinic, and the questionnaires were administered before contact lens purchase. Teikari et al. ${ }^{10}$ reported much higher sensitivity (0.98) and specificity (0.95) in a four-item questionnaire, which asked about spectacle use and vision perception and included the question "Do you see well at a far distance when looking with both your eyes and without your glasses?" The sampled population (twins aged 30-31 years) in this study had a low prevalence of moderate hyperopia, which may have made myopia easier to be detected on questionnaire.

In the study by Liang et al. ${ }^{3}$ among Taiwanese participants aged 17 to 45 years, false report rates for parental myopia were extremely low (2\%). Participants included Taiwanese university and high school students, hospital personnel, and military conscripts. The vast majority ( $84 \%$ ) of Taiwanese young adults (age 16-18 years) have myopia, ${ }^{14}$ so that the use of myopia questionnaires in populations with high myopia prevalence may not be comparable to their use in other populations with much lower myopia prevalence.

Limitations of the current study include the relatively small numbers of parents with hyperopia and astigmatism, which could have partly contributed to the low sensitivities for predicting these two refractive conditions. Alternately, information obtained from the questionnaire used in this study may not be sufficient to predict hyperopia or astigmatism. Questions about spectacle use to identify hyperopia have been largely inaccurate. ${ }^{10,11}$ Spectacles worn for moderate hyperopia are often used for both distance and near work, similar to their use by myopic subjects, making hyperopia difficult to distinguish from myopia. In younger populations, where the prevalence of myopia is higher than hyperopia, this difficulty is likely to be compounded.

Impaired vision has been shown to have a significant impact on function and well-being, ${ }^{15}$ and in Australia, where optometric (vision testing) services are widely available and are largely covered by a universal health insurance system (Medicare), spectacle prescription is a reasonable surrogate for the presence of refractive error status. Using spectacle prescriptions as the gold standard, however, could have a potential weakness, particularly in parents for whom no prescriptions were provided despite the presence of refractive errors, or where the prescriptions were inaccurate. The latter was found to be relatively common in older populations, as vision could be improved in a high proportion $(45 \%)$ by a new distance prescription. ${ }^{16}$

In the current questionnaire, refractive errors that may be misclassified as myopia included anisometropia, and astigmatism with or without hyperopia. The magnitude of misclassification by using a questionnaire will likely depend on the prevalence of these refractive errors. Among Caucasian adult populations aged 40-49 years in the United States, the prevalence of anisometropia was found to be low $(5.5 \%$ in women and $6.3 \%$ in men), whereas the prevalence of astigmatism was substantially higher (27.7\% in women and $30.1 \%$ in men); ${ }^{17}$ thus, we would expect a greater proportion of misclassification for astigmatism than for anisometropia in using this questionnaire tool.

In summary, we verified that a relatively simple, selfadministered questionnaire may be used in adults with reasonable accuracy for identifying myopia cases (with fairly high sensitivity and specificity), even when used in a general 
adult population with a relatively low myopia prevalence. The use of such questionnaires is both cost-effective and far less time-consuming than measuring refraction and thus may be considered useful for surveys and screening purposes.

\section{ACKNOWLEDGEMENTS}

The Sydney Myopia Study is supported by the Australian National Health \& Medical Research Council (Grant No. 253732), the Westmead Millennium Institute, University of Sydney and the Vision Co-operative Research Centre.

\section{REFERENCES}

1. Saw SM, Nieto FJ, Katz J, Schein OD, Levy B, Chew SJ. Familial clustering and myopia progression in Singapore school children. Ophthalmic Epidemiol. 2002;8:227-236.

2. Yap M, Wu M, Liu ZM, Lee FL, Wang SH. Role of heredity in the genesis of myopia. Ophthalmic Physiol Opt. 1993;13:316319.

3. Liang CL, Yen E, Su JY, Liu C, Chang TY, Park N, et al. Impact of family history of high myopia on level and onset of myopia. Invest Ophthalmol Vis Sci. 2004;45:3446-3452.

4. Zadnik K, Satariano WA, Mutti DO, Sholtz RI, Adams AJ. The effect of parental history of myopia on children's eye size. JAMA. 1994;271:1323-1327.

5. Saw SM, Carkeet A, Chia KS, Stone RA, Tan DT. Component dependent risk factors for ocular parameters in Singapore Chinese children. Ophthalmology. 2002;109:2065-2071.

6. Saw SM, Chua WH, Gazzard G, Koh D, Tan DT, Stone RA. Eye growth changes in myopic children in Singapore. Br.J Ophthalmol. 2005;89:1489-1494.
7. Lee KE, Klein BE, Klein R, Fine JP. Aggregation of refractive error and 5-year changes in refractive error among families in the Beaver Dam Eye Study. Arch Ophthalmol. 2001;119:16791685.

8. Familial aggregation and prevalence of myopia in the Framingham Offspring Eye Study. The Framingham Offspring Eye Study Group. Arch Ophthalmol. 1996;114:326-332.

9. Mutti DO, Mitchell GL, Moeschberger ML, Jones LA, Zadnik K. Parental myopia, near work, school achievement, and children's refractive error. Invest Ophthalmol Vis Sci. 2002;43:3633-3640.

10. Teikari JM, Kaprio J, Koskenvuo M, O'Donnell J. Heritability of defects of far vision in young adults-a twin study. Scand $J$ Soc Med. 1992;20:73-78.

11. Walline JJ, Zadnik K, Mutti DO. Validity of surveys reporting myopia, astigmatism, and presbyopia. Optom Vis Sci. 1996;73:376381.

12. Ojaimi E, Rose KA, Smith W, Morgan IG, Martin FJ, Mitchell P. Methods for a population-based study of myopia and other eye conditions in school children: the Sydney Myopia Study. Ophthalmic Epidemiol. 2005;12:59-69.

13. Iribarren R, Iribarren G, Castagnola MM, Balsa A, Cerrella MR, Armesto A, et al. Family history and reading habits in adult-onset myopia. Curr Eye Res. 2002;25:309-315.

14. Lin LL, Shih YF, Tsai CB, Chen CJ, Lee LA, Hung PT, et al. Epidemiologic study of ocular refraction among schoolchildren in Taiwan in 1995. Optom Vis Sci. 1999;76:275-281.

15. Scott IU, Smiddy WE, Schiffman J, Feuer WJ, Pappas CJ. Quality of life of low-vision patients and the impact of low-vision services. Am J Ophthalmol. 1999;128:54-62.

16. Attebo $\mathrm{K}$, Mitchell $\mathrm{P}, \mathrm{Smith} \mathrm{W}$. Visual acuity and the causes of visual loss in Australia. The Blue Mountains Eye Study. Ophthalmology. 1996;103:357-364.

17. Katz J, Tielsch JM, Sommer A. Prevalence and risk factors for refractive errors in an adult inner city population. Invest Ophthalmol Vis Sci. 1997;38:334-340. 